\title{
Thoracoscopic Management of Traumatic Sequelae
}

\author{
Laura Godat $^{1} \cdot$ Emily Cantrell $^{1} \cdot$ Raul Coimbra $^{1}$
}

Published online: 30 April 2016

(C) Springer International Publishing AG 2016

\begin{abstract}
Video-assisted thoracoscopic surgery can be beneficial for patients with penetrating and blunt thoracic trauma. It has utility in the initial assessment as well as the management of sequelae of traumatic injuries, especially retained hemothorax, and should be part of any trauma surgeon's skill set. This review intends to emphasize the best-supported indications and timing for the use of this surgical approach in the injured patient.
\end{abstract}

Keywords Video-assisted thoracoscopic surgery · Thoracic trauma $\cdot$ Hemothorax $\cdot$ Retained hemothorax

\section{Introduction}

The incidence of thoracic trauma is high. In the USA, the National Trauma Data Bank 2015 annual report cited that $21.4 \%$ of trauma patients had a reported thoracic injury. For those patients with an abbreviated injury score of $\geq 3$, the case fatality rate was $9.7 \%$ [1]. A 10-year experience from Turkey reported similar mortality rates of $9.3 \%$ among 3575 patients with chest trauma [2].

In 1910, Jacobaeus of Stockholm, Sweden was first to report the use of thoracoscopy for evaluation of the human tho$\operatorname{rax}[3]$. As for thoracic trauma, the first report of thoracoscopy

This article is part of the Topical Collection on Minimally Invasive Surgical Techniques for Trauma

Raul Coimbra

rcoimbra@ucsd.edu

1 San Diego Health Sciences, University of California, $200 \mathrm{~W}$ Arbor Dr. \#8896, San Diego, CA 92103, USA was by Branco of Rio de Janeiro, Brazil in 1946, for the initial evaluation of injury and need for thoracotomy in five patients [4]. Then, in 1980, during the 40th annual session of the American Association for the Surgery of Trauma, Drs. Jones and McSwain from Tulane University presented their experience on the use of emergency thoracoscopy for the initial evaluation of a hemothorax in 36 stable penetrating trauma patients, citing its benefit in the diagnosis of diaphragmatic injury, treatment of minor bleeding, and evacuation of clotted blood [5]. This review will describe current evidence-based principles for the use of video-assisted thoracoscopic surgery (VATS) in the early identification of injuries and the management thoracic trauma sequelae, focusing on its application in patients with retained hemothorax.

\section{Indications for Surgery}

Thoracoscopy is not an approach to be used in the initial assessment of hemodynamically unstable injured patients. However, there are some applications in which thoracoscopy can be used in the evaluation and management of patients with chest trauma.

\section{Initial Exploration}

Jones et al. published one of the largest early studies in 1981, reporting on the use of VATS in the initial evaluation of patients with hemothoraces. They found that thoracotomy could be avoided in the majority of stable patients with high chest tube output (10 of 11 patients), and bleeding was stopped in most cases with electrocautery [5]. In 2011, a group from Turkey conducted a randomized controlled trial comparing standard tube thoracostomy placement to immediate VATS on patients who presented with hemothorax. They found that 
patients who underwent VATS had shorter length of stay and less morbidity, i.e., empyema and fibrothorax [6].

The other potential indication of VATS in hemodynamically stable patients may include penetrating thoracoabdominal injuries to rule out diaphragmatic injury. Thoracoscopic exploration via a chest tube site, if negative for diaphragmatic injury, obviates the need for laparoscopy, facilitates evacuation of any residual hemothorax, and ensures a well-placed chest tube [5, 7-9]. In 2009, Bagheri et al. analyzed their experience with 30 patients and reported no missed diaphragmatic injuries [10]. Their finding supports the use of VATS for the initial diagnosis of diaphragmatic injury $[10,11]$, though if identified, laparotomy should be undertaken to evaluate for intraabdominal injury.

Pulmonary injuries or intrathoracic sources of bleeding, i.e., intercostal vessels, can be identified and potentially managed in a minimally invasive fashion [12]. Goodman et al. reported on their experience with early VATS, defined as the first $24 \mathrm{~h}$ after injury in hemodynamically stable patients. They were able to manage bleeding, perform lung resection, chest wall hemostasis, identify diaphragmatic injuries, and evaluate for mediastinal injuries. They concluded that VATS is a safe and effective management strategy in stable patients with chest trauma [13]. This concept is also supported by Chou et al. who showed evidence of better outcomes in patients who had lung repair at the time of VATS, including shorter duration of mechanical ventilation and time to chest tube removal [14•].

Another reported indication of VATS, although not well founded, is the removal of foreign bodies, including bullets $[12,15-18]$. In addition, the use of VATS has been reported in the evaluation of a potential cardiac injury and to perform a pericardial window [11, 19]. At this time, we cannot recommend these as safe and effective management options due to lack of evidence.

\section{Retained Hemothorax}

It is estimated that over one third of all patients with chest trauma will require a tube thoracostomy to treat a traumatic hemothorax. While tube thoracostomy alone will be sufficient in the majority of cases, a retained hemothorax can occur in approximately $5 \%$ of cases [20-22]. Known sequela of retained hemothorax includes fibrothorax, lung entrapment, and empyema. The diagnosis of retained hemothorax can be made with the use of plain chest radiographs or computed tomography (CT) of the chest. Once identified, the optimal method for evacuation of the hemothorax is a topic of ongoing research. Various management options include observation, placement of additional thoracostomy tubes, use of intrapleural thrombolytic drugs, VATS, and thoracotomy. In light of the growing use of minimally invasive techniques, VATS has been shown to be a safe and effective method in addressing retained clot following initial chest tube placement for hemothorax [20, 21, 23-34].

In order to treat a retained hemothorax, it is first important to define when and how it is diagnosed. Meyer et al. defined it as persistent hemothorax on plain film radiograph $72 \mathrm{~h}$ after initial chest tube placement [25]. This is also supported by Lin et al., a more recent 2014 study, demonstrating that the diagnosis should be made within $48-72 \mathrm{~h}$ of chest tube placement [35•0]. Figure 1a demonstrates a suspected retained hemothorax on chest radiograph $48 \mathrm{~h}$ after injury.

Once a retained hemothorax is suspected on plain film radiograph, those patients who require VATs need to be identified. It is recommended that a chest CT (Fig. 1b) be used to confirm the diagnosis of retained hemothorax and to calculate its volume $[31,36 \bullet \cdot]$. The volume of $500 \mathrm{cc}$ has been postulated as the threshold for defining patients who are unlikely to be successfully managed without surgical intervention, since this is the amount needed to be seen on plain chest radiograph $[24,37]$. Dubose et al. were able to determine that a volume of less than $300 \mathrm{cc}$ estimated by chest CT was a significant predictor of successful non-operative management $[36 \bullet \bullet$.

In order to decrease potential subsequent complications from retained hemothoraces such as empyema or lung entrapment, the data favors "early" surgical evacuation of a retained hemothorax over observation or placement of additional thoracostomy tubes [25]. Morales et al. analyzed their experience with 139 patients to help define how early VATS should be performed. They report that when performed more than 5 days after initial injury, there was a twofold increased risk of conversion to thoracotomy or need for re-intervention [27]. In a retrospective review, Smith et al. had similar findings, reporting that patients undergoing early VATS, $<5$ days postinjury, for retained hemothorax had decreased hospital length of stay and decreased conversion rates to open thoracotomy, whereas patients undergoing VATS more than 5 days after the initial injury had an increased rate of empyema formation [38].

In a prospective randomized trial, Meyer et al. showed that patients who were randomized to undergo VATS for retained hemothorax at $72 \mathrm{~h}$ following initial chest tube placement had decreased duration of chest tube drainage, decreased hospital length of stay, and decreased hospital costs when compared with counterparts who underwent placement of a second chest tube [25]. In contrast, a prospective, multi-center, observational trial by the AAST failed to find any association between the timing and the success rate of VATS. The authors also noted that, while VATS was a successful method for managing retained clot, approximately $25 \%$ of patients required at least two procedures to effectively remove the retained clot and up to $20 \%$ of patients required thoracotomy, 

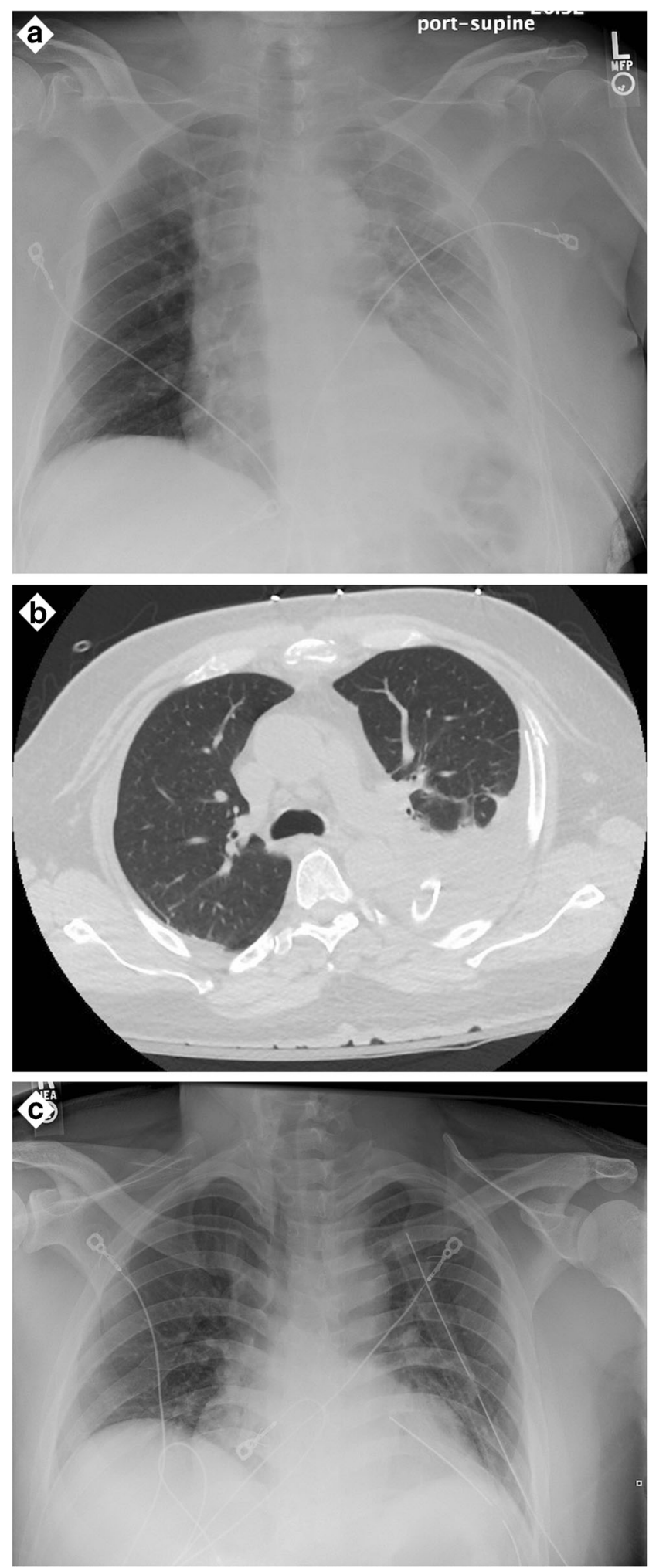

Fig. 1 a Plain film chest radiograph of a patient with suspected retained hemothorax $48 \mathrm{~h}$ after chest tube placement. b Chest CT demonstrating retained hemothorax. $\mathbf{c}$ Plain film chest radiograph postoperative day 1 from VATS performed $24 \mathrm{~h}$ after diagnosis

most often for large volumes of clot $(>900 \mathrm{ml})$ or for associated diaphragmatic injury $[36 \bullet \bullet]$.
Success rates for VATS in the management of retained hemothorax have been relatively high (up to $90 \%$ ) with an overall low conversion rate to open thoracotomy (10\% or less) [39]. Figure $1 \mathrm{c}$ shows a plain film chest radiograph after successful VATS for retained hemothorax. VATS has also been shown to be superior to placement of additional chest tubes and intrapleural thrombolytic therapy $[25,40]$. In a retrospective review, Oguzkaya et al. found that while intrapleural thrombolytic therapy can be an effective alternative in the management of retained hemothorax, patients who underwent this form of therapy had longer hospital length of stay and a higher failure rate when compared to patients undergoing VATS [40].

Although most of the research regarding the use of VATS in retained hemothorax has been focused on the general trauma population, it also seems to be a feasible management option in the elderly population. These patients are often at increased risk for both morbidity and mortality due to their age and medical comorbidities. Schweigert et al. argued that advanced age should not be an absolute contraindication or a reason for delay in performing VATS. In their study, all octogenarian patients underwent successful VATS without any in-hospital mortality despite sometimes prolonged postoperative course. Delayed time to surgery was the main issue identified in the care of elderly patients with chest trauma [41•].

Due to the potential advantages of small incisions, including less pain and faster recovery times, the popularity of VATS in the management of chest trauma has increased tremendously over the last two decades. In addition, outcomes such as effectiveness, perioperative morbidity and mortality, and hospital length of stay following VATS also seem to be superior to open thoracotomy in treating hemodynamically stable patients with chest trauma. In a recent meta-analysis, Wu et al. conducted a systematic review of 26 randomized controlled trials and cohort studies from the Chinese literature. They compared the perioperative outcomes of VATS to open thoracotomy in patients sustaining chest trauma. Compared to open thoracotomy, patients undergoing VATS for chest trauma were noted to have significantly reduced perioperative complications, decreased chest tube drainage volume and duration of chest tube drainage, reduced hospital length of stay, shorter operative times, and decreased blood loss and transfusion requirements. No significant differences were noted in perioperative mortality $[42 \bullet \bullet]$.

VATS can be safely and effectively performed by acute care surgeons [38]. With VATS being more frequently utilized in the management of retained hemothorax at the discretion of acute care and trauma surgeons, having a clinical pathway incorporating VATS into the management algorithm may prove useful. Morrison et al. showed that implementation of a clinical pathway for early evacuation of retained hemothorax improved patient outcomes and decreased hospital cost [22]. 
Within 1 year of each other, two leading trauma groups published similar yet somewhat contradictory sets of guidelines for the timing of VATS in the management of retained hemothorax. The Eastern Association for the Surgery of Trauma (EAST) recommended VATS within 3-5 days of hospitalization [43]. However, the Evidence-Based Telemedicine-Trauma and Acute Care Surgery (TBECITE) group recommended that VATS should be performed within 3-5 days after the diagnosis of a retained hemothorax [44]. We believe that these differences in timing exist due to a lack of consensus for when a retained hemothorax is diagnosed.

The growing amount of evidence that we have presented in this manuscript allows us to suggest a clear definition for when a hemothorax becomes a retained hemothorax and recommendations for its early treatment. We propose that a clinically significant retained hemothorax should be defined as $>300 \mathrm{cc}$ of blood present on chest CT at 48 to $72 \mathrm{~h}$ from the time of initial chest tube insertion. Therefore, early VATS should be defined as 24-72 $\mathrm{h}$ after the diagnosis of retained hemothorax, without exceeding 5 days after initial chest tube placement. Figure 2 outlines our proposed clinical management algorithm for patients presenting with hemothorax.

\section{Posttraumatic Empyema}

Empyema is another known sequela in patients sustaining significant chest trauma. While the diagnosis and management of posttraumatic empyema remains a topic of debate, the incidence of empyema in those who have sustained thoracic injuries ranges from 2 to $30 \%$ [45, 46••]. Multiple risk factors have been identified as being associated with the development of posttraumatic empyema including retained hemothorax, prolonged duration of tube thoracostomy, need for exploratory laparotomy, diaphragmatic injury, presence of pulmonary contusion, presence of rib fractures, Injury Severity Score (ISS) equal or greater than 25, and need for additional interventions to evacuate retained blood in the tho$\operatorname{rax}[45,46 \bullet \bullet, 47]$.

Mandal et al., in a review of 5474 patients undergoing tube thoracostomy for chest trauma, identified retained hemothorax as a risk factor for the development of posttraumatic empyema [47]. In a 17-year retrospective study of 2261 patients with chest trauma requiring tube thoracostomy, Eren et al. noted that empyema developed in $3.1 \%$ and that duration of tube thoracostomy, ICU length of stay, presence of pulmonary contusion or retained hemothorax, and need for exploratory
Fig. 2 Clinical management algorithm for retained hemothorax

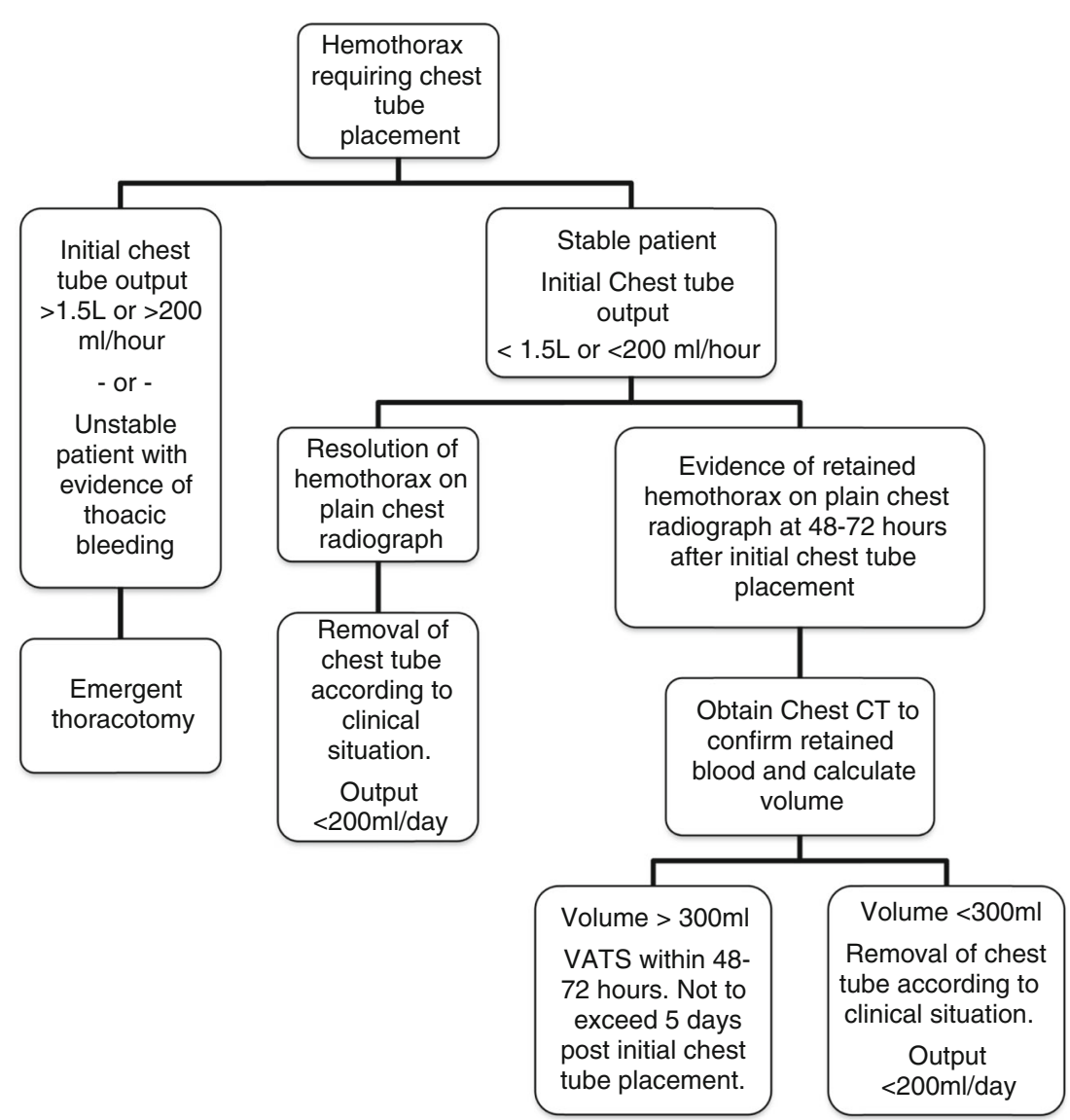


laparotomy were all independent predictors for the development of empyema [45]. Finally, in a prospective, multi-center observational study, Dubose et al. noted a $26.8 \%$ incidence of posttraumatic empyema in the setting of retained hemothorax. Independent risk factors of empyema development following posttraumatic retained hemothorax included the presence of rib fractures, ISS equal to or greater than 25 , and the need for additional interventions to evacuate retained blood from the thorax $[46 \bullet \bullet$.

When compared to patients without empyema, patients who develop posttraumatic empyema have also been found to have significantly longer ICU and hospital stay as well as increased hospital costs $[45,46 \cdot \bullet, 47]$. While the best course of management remains unclear, VATS is an effective option for treating empyema in selected patients, particularly when performed early. However, the diagnosis of empyema has been shown to be a predictor of increased conversion to thoracotomy to adequately treat the infection. Smith et al. reported the rate of conversion from VATS to thoracotomy being $73 \%$ for empyema, compared to $4.9 \%$ for retained hemothorax and $0 \%$ for persistent airleak [38].

\section{Thoracic Duct Injury}

Chylothorax can develop after penetrating trauma to the chest. Patients at especially high risk include those with trauma in the left supraclavicular area or in the mediastinum. For those that persist without improvement for more than 2 weeks despite optimal medical management, thoracoscopic thoracic duct ligation may be considered [7]. No large series for traumatic chylothorax could be identified, but this approach is reported in the literature with success $[48,49]$.

\section{Summary}

The use of VATS in trauma has been described in the literature for almost a century. In the initial treatment of the injured patient, there is evidence in support of diagnostic VATS for hemodynamically stable patients. Initial treatment of injury by VATS is also described for pulmonary injuries and to obtain hemostasis particularly when bleeding is caused by intercostal vessel injury; however, the evidence for these two indications is not robust. The greatest amount of solid evidence in the literature supporting the use of VATS in trauma is in patients with retained hemothorax. In those cases, early VATS seems to be a safe and effective surgical management option, since a delay carries a higher risk of empyema, fibrothorax, and conversion to thoracotomy.

\section{Conclusions and Recommendations}

1. VATS can safely and effectively be used in hemodynamically stable trauma patients to diagnose intrathoracic injuries, though the surgeon must be prepared to convert to thoracotomy or undergo laparotomy if needed.

2 . VATS is most useful in the treatment of clinically significant retained hemothorax, diagnosed at $48-72 \mathrm{~h}$ after chest tube placement. A CT of the chest should be obtained to make the diagnosis; the finding of $\geq 300 \mathrm{cc}$ of blood qualifies it as a clinically significant retained hemothorax. VATS should then be performed early and aggressively (within 48-72 h of diagnosis) to facilitate recovery and prevent additional morbidity. 3. Though VATS is effective in the treatment of empyema following trauma, the better approach is the early treatment of retained hemothorax to prevent occurrence of an empyema.

\section{Compliance with Ethical Standards}

Conflict of Interest Drs. Coimbra, Godat, and Cantrell declare no conflicts of interest.

Human and Animal Rights and Informed Consent This article does not contain any studies with human or animal subjects performed by any of the authors.

\section{References}

Papers of particular interest, published recently, have been highlighted as:

- Of importance

•- Of major importance

1. Committee on Trauma, American College of Surgeons. National Trauma Data Bank annual report 2015. https://www.facs.org/ $\sim /$ media/files/quality $\% 20$ programs/trauma/ntdb/ntdb $\% 20$ annual $\%$ 20report\%202015.ashx. Accessed January 6, 2016.

2. Demirhan R, Onan B, Oz K, Halezeroglu S. Comprehensive analysis of 4205 patients with chest trauma: a 10-year experience. Interact Cardiovasc Thorac Surg. 2009;9(3):450-3. doi:10.1510/ icvts.2009.206599.

3. Jacobaeus HC. Possibility of the use of the cystoscope for investigation of serous cavities. Munchner Meditinische Wochenschrift. 2010;57:2090-2.

4. Martins Castello Branco J. Thoracoscopy as a method of exploration in penetrating injuries of the thorax. Dis Chest. 1946;12:330-5.

5. Jones JW, Kitahama A, Webb WR, McSwain N. Emergency thoracoscopy: a logical approach to chest trauma management. J Trauma. 1981;21(4):280-4.

6. Cobanoglu U, Sayir F, Mergan D. Should videothorascopic surgery be the first choice in isolated traumatic hemothorax? A prospective randomized controlled study. Ulusal travma ve acil cerrahi dergisi = Turk J Trauma Emerg Surg : TJTES. 2011;17(2):117-22.

7. Demetriades D, Velmahos GC. Penetrating injuries of the chest: indications for operation. Scand J Surg : SJS : Off Organ for the Finn Surg Soc Scand Surg Soc. 2002;91(1):41-5. 
8. Ochsner MG, Rozycki GS, Lucente F, Wherry DC, Champion HR. Prospective evaluation of thoracoscopy for diagnosing diaphragmatic injury in thoracoabdominal trauma: a preliminary report. $\mathrm{J}$ Trauma. 1993;34(5):704-9. Discussion 9-10.

9. Ben-Nun A, Orlovsky M, Best LA. Video-assisted thoracoscopic surgery in the treatment of chest trauma: long-term benefit. Ann Thorac Surg. 2007;83(2):383-7. doi:10.1016/j.athoracsur.2006. 09.082 .

10. Bagheri R, Tavassoli A, Sadrizadeh A, Mashhadi MR, Shahri F, Shojaeian R. The role of thoracoscopy for the diagnosis of hidden diaphragmatic injuries in penetrating thoracoabdominal trauma. Interact Cardiovasc Thorac Surg. 2009;9(2):195-7. Discussion 7-8.

11. Freeman RK, Al-Dossari G, Hutcheson KA, Huber L, Jessen ME, Meyer DM, et al. Indications for using video-assisted thoracoscopic surgery to diagnose diaphragmatic injuries after penetrating chest trauma. Ann Thorac Surg. 2001;72(2):342-7.

12. Milanchi S, Makey I, McKenna R, Margulies DR. Video-assisted thoracoscopic surgery in the management of penetrating and blunt thoracic trauma. J Minimal Access Surg. 2009;5(3):63-6.

13. Goodman M, Lewis J, Guitron J, Reed M, Pritts T, Starnes S. Video-assisted thoracoscopic surgery for acute thoracic trauma. J Emerg Trauma Shock. 2013;6(2):106-9.

14. Chou YP, Kuo LC, Soo KM, Tarng YW, Chiang HI, Huang FD, et al. The role of repairing lung lacerations during video-assisted thoracoscopic surgery evacuations for retained haemothorax caused by blunt chest trauma. Eur J Cardio Thorac Surg : Off J Eur Assoc Cardio Thorac Surg. 2014;46(1):107-11. This article is a prospective analysis of the management of lung injuries using VATS. They report improved outcomes in patients with lung lacerations who had a lung resection at the time of VATS.

15. Khalil MW, Khan T, Gower S, Loubani M. Removal of a bullet in the pericardial cavity by video-assisted thoracoscopic surgery. Interact Cardiovasc Thorac Surg. 2012;15(2):297-8.

16. Isenburg $\mathrm{S}$, Jackson $\mathrm{N}$, Karmy-Jones R. Removal of an impaled knife under thoracoscopic guidance. Can Respir J : J Can Thorac Soc. 2008;15(1):39-40.

17. Marsico GA, Almeida AL, Azevedo DE, Venturini GC, Azevedo AE, Marsico Pdos S. Video-assisted thoracoscopic removal of foreign bodies from the pleural cavity. Jornal brasileiro de pneumologia : publicacao oficial da Sociedade Brasileira de Pneumologia e Tisilogia. 2008;34(4):241-4.

18. Komatsu T, Neri S, Fuziwara Y, Takahashi Y. Video-assisted thoracoscopic surgery (VATS) for penetrating chest wound: thoracoscopic exploration and removal of a penetrating foreign body. Can J Surg Journal canadien de chirurgie. 2009;52(6): E301-2.

19. Andrade-Alegre R. Pericardioscopy for diagnosing penetrating cardiac trauma. Ann Thorac Surg. 2015;99(5):e115-6.

20. Heniford BT, Carrillo EH, Spain DA, Sosa JL, Fulton RL, Richardson JD. The role of thoracoscopy in the management of retained thoracic collections after trauma. Ann Thorac Surg. 1997;63(4):940-3.

21. Abolhoda A, Livingston DH, Donahoo JS, Allen K. Diagnostic and therapeutic video assisted thoracic surgery (VATS) following chest trauma. Eur J Cardio thorac Surg : Off J Eur Assoc Cardio Thorac Surg. 1997;12(3):356-60.

22. Morrison CA, Lee TC, Wall Jr MJ, Carrick MM. Use of a trauma service clinical pathway to improve patient outcomes for retained traumatic hemothorax. World J Surg. 2009;33(9):1851-6.

23. Milfeld DJ, Mattox KL, Beall Jr AC. Early evacuation of clotted hemothorax. Am J Surg. 1978;136(6):686-92.

24. Vassiliu P, Velmahos GC, Toutouzas KG. Timing, safety, and efficacy of thoracoscopic evacuation of undrained post-traumatic hemothorax. Am Surg. 2001;67(12):1165-9.
25. Meyer DM, Jessen ME, Wait MA, Estrera AS. Early evacuation of traumatic retained hemothoraces using thoracoscopy: a prospective, randomized trial. Ann Thorac Surg. 1997;64(5):1396-400. Discussion 400-1.

26. Navsaria PH, Vogel RJ, Nicol AJ. Thoracoscopic evacuation of retained posttraumatic hemothorax. Ann Thorac Surg. 2004;78(1): 282-5. Discussion 5-6.

27. Morales Uribe CH, Villegas Lanau MI, Petro Sanchez RD. Best timing for thoracoscopic evacuation of retained post-traumatic hemothorax. Surg Endosc. 2008;22(1):91-5.

28. Scherer LA, Battistella FD, Owings JT, Aguilar MM. Videoassisted thoracic surgery in the treatment of posttraumatic empyema. Arch Surg. 1998;133(6):637-41. Discussion 41-2.

29. Liu DW, Liu HP, Lin PJ, Chang CH. Video-assisted thoracic surgery in treatment of chest trauma. J Trauma. 1997;42(4):670-4.

30. Lowdermilk GA, Naunheim KS. Thoracoscopic evaluation and treatment of thoracic trauma. Surg Clin North Am. 2000;80(5): $1535-42$.

31. Velmahos GC, Demetriades D, Chan L, Tatevossian R, Cornwell 3rd EE, Yassa N, et al. Predicting the need for thoracoscopic evacuation of residual traumatic hemothorax: chest radiograph is insufficient. J Trauma. 1999;46(1):65-70.

32. Villavicencio RT, Aucar JA, Wall Jr MJ. Analysis of thoracoscopy in trauma. Surg Endosc. 1999;13(1):3-9.

33. Wong MS, Tsoi EK, Henderson VJ, Hirvela ER, Forest CT, Smith RS, et al. Videothoracoscopy an effective method for evaluating and managing thoracic trauma patients. Surg Endosc. 1996;10(2): 118-21.

34. Fabbrucci P, Nocentini L, Secci S, Manzoli D, Bruscino A, Fedi M, et al. Video-assisted thoracoscopy in the early diagnosis and management of post-traumatic pneumothorax and hemothorax. Surg Endosc. 2008;22(5):1227-31.

35.• Lin HL, Huang WY, Yang C, Chou SM, Chiang HI, Kuo LC, et al. How early should VATS be performed for retained haemothorax in blunt chest trauma? Injury. 2014;45(9):1359-64. A retrospective study to determine the optimal timing from admission to VATS. This study reports that VATS done prior to postinjury day 6 decreases ICU and hospital length of stay, time on the ventilator, and infections.

36.• DuBose J, Inaba K, Demetriades D, Scalea TM, O'Connor J, Menaker J, et al. Management of post-traumatic retained hemothorax: a prospective, observational, multicenter AAST study. J Trauma Acute Care Surg. 2012;72(1):11-22. Discussion -4; quiz. A large multi-institutional trial to determine the incidence of retained hemothorax and optimal management strategy. Unlike other trials, they did not find a relationship between timing of VATS and successful treatment of retained hemothorax.

37. Velmahos GC, Demetriades D. Early thoracoscopy for the evacuation of undrained haemothorax. Eur J Surg = Acta chirurgica. 1999;165(10):924-9.

38. Smith JW, Franklin GA, Harbrecht BG, Richardson JD. Early VATS for blunt chest trauma: a management technique underutilized by acute care surgeons. J Trauma. 2011;71(1):1025. Discussion 5-7.

39. Billeter AT, Druen D, Franklin GA, Smith JW, Wrightson W, Richardson JD. Video-assisted thoracoscopy as an important tool for trauma surgeons: a systematic review. Langenbeck's Arch Surg / Deutsche Gesellschaft fur Chirurgie. 2013;398(4):515-23.

40. Oguzkaya F, Akcali Y, Bilgin M. Videothoracoscopy versus intrapleural streptokinase for management of post traumatic retained haemothorax: a retrospective study of 65 cases. Injury. 2005;36(4):526-9.

41. Schweigert M, Beron M, Dubecz A, Stadlhuber R, Stein H. Videoassisted thoracoscopic surgery for posttraumatic hemothorax in the very elderly. Thorac Cardiovasc Surg. 2012;60(7):474-9. An 
important investigation to guide management of elderly trauma patients and improve outcomes. This study supports the use of VATS in elderly patients and suggests that early and aggressive management should apply to this population.

42.• Wu N, Wu L, Qiu C, Yu Z, Xiang Y, Wang M, et al. A comparison of video-assisted thoracoscopic surgery with open thoracotomy for the management of chest trauma: a systematic review and metaanalysis. World J Surg. 2015;39(4):940-52. A large metaanalysis of studies in the Chinese literature analyzing of the impact of VATS on perioperative morbidity when compared to thoracotomy for patients with thoracic trauma. In this study, VATS was associated with a significant decrease in postoperative complications and a trend toward improved perioperative mortality.

43. Mowery NT, Gunter OL, Collier BR, Diaz Jr JJ, Haut E, Hildreth A, et al. Practice management guidelines for management of hemothorax and occult pneumothorax. J Trauma. 2011;70(2):510-8.

44. de Rezende-Neto JB, Pastore Neto M, Hirano ES, Rizoli S, Nascimento Jr B, Fraga GP. Management of retained hemothoraces after chest tube thoracostomy for trauma. Revista do Colegio Brasileiro de Cirurgioes. 2012;39(4):344-9.
45. Eren S, Esme H, Sehitogullari A, Durkan A. The risk factors and management of posttraumatic empyema in trauma patients. Injury. 2008;39(1):44-9.

46.• DuBose J, Inaba K, Okoye O, Demetriades D, Scalea T, O’Connor $\mathrm{J}$, et al. Development of posttraumatic empyema in patients with retained hemothorax: results of a prospective, observational AAST study. J Trauma Acute Care Surg. 2012;73(3):752-7. This is a large, prospective multi-institutional trial including 328 patients. They report an empyema incidence of $26.8 \%$. Significant predictors of empyema were needed for multiple interventions to evacuate a retained hemothorax, rib fractures, and an injury severity score $\geq \mathbf{2 5}$.

47. Mandal AK, Thadepalli H, Chettipalli U. Posttraumatic empyema thoracis: a 24-year experience at a major trauma center. J Trauma. 1997;43(5):764-71.

48. Buchan KG, Hosseinpour AR, Ritchie AJ. Thoracoscopic thoracic duct ligation for traumatic chylothorax. Ann Thorac Surg. 2001;72(4):1366-7.

49. Zabeck H, Muley T, Dienemann H, Hoffmann H. Management of chylothorax in adults: when is surgery indicated? Thorac Cardiovasc Surg. 2011;59(4):243-6. 